\title{
Epidemiology of infertility and characteristics of infertile couples requesting assisted reproduction in a low- resource setting in Africa, Sudan
}

\author{
Osama G. Elhussein ${ }^{1}$, Mohamed A. Ahmed², Suliman O. Suliman³ , leena I. Yahya ${ }^{2}$ and Ishag Adam² (1)
}

\begin{abstract}
Background: Infertility is a big health problem worldwide. Few data exist on infertility in Sudan.

Methods: A descriptive study was conducted to assess the pattern and the causes of infertility among couples (800) attending the University of Khartoum Fertility Centre, Saad Abualila Teaching Hospital in Khartoum, Sudan. The data on the socio-demographic characteristics of the patients, the type of infertility whether primary or secondary and the causes of infertility were extracted from the medical files retrospectively.

Results: The mean (SD) age of the females was 32.4 (7.4) years while that of the males was 37.5 (7.2) years. The mean (SD) duration of infertility was 4.9(3.9) years. Five hundred and fifty one (68.9\%) couples had primary infertility, while the remainder 249(31.1\%) had secondary infertility. Two hundred and eighty four (35.5\%) couples had male infertility, $342(42.8 \%)$ couples had female infertility. One hundred and forty seven (18.4\%) couples had combined male and female infertility and in 27 (3.4\%) couples the cause of infertility was not identified. Factors identified in the female infertility (342) were; anovulation (178, 52.05\%), tubal factor (142, 41.52\%), uterine factor (7, 2.05\%) and other/combined $(7,2.05 \%)$. Azoospermia (75, 26.41\%), oligozoospermia (45, 15.85\%), asthenozoospermia (51, 17.96\%), teratospermia (15, $5.28 \%)$ and mixed pathology $(101,35.56 \%)$ were the causes of the male infertility $(n=284)$. Female factors of infertility were observed more frequently among couples with secondary infertility compared with primary infertility (143/ 551 (57.4) vs. 199/249(36.1), $P<0.001$.

Conclusion: The current study showed a high rate of primary infertility and female factor predominates compared with male factors. Future research direction should focus on the reasons why majority of clients seek this service very late.
\end{abstract}

Keywords: Infertility, Male, Female, Tubal factor, Ovulation, Sudan

\section{Background}

Infertility is a big health problem worldwide as it has been estimated that in 2010 there are 48.5 million (45.0 million, 52.6 million) infertile couples worldwide [1]. World Health Organization (WHO) defines infertility as "a disease of the reproductive system defined by the failure to achieve a clinical pregnancy after 12 months or more of regular unprotected sexual intercourse" [2].

\footnotetext{
* Correspondence: ishagadam@hotmail.com

${ }^{2}$ Department of Obstetrics and Gynecology, Faculty of Medicine, University of Khartoum, 11111 Khartoum, Sudan

Full list of author information is available at the end of the article
}

Meanwhile the WHO's epidemiologic definition of infertility as "women of reproductive age at risk of becoming pregnant who report unsuccessfully trying for a pregnancy for more than two years" [3].

Among the various regions in the world, South East Asia and Sub-Saharan Africa countries have the highest prevalence of infertility [1]. Different causes and types of infertility were reported in the different African countries [4-7]. Investigating the types and causes of infertility is highly needed to generate data important for planning and interventions. While there is much data of infertility in high-income countries as well as in other

(c) The Author(s). 2019 Open Access This article is distributed under the terms of the Creative Commons Attribution 4.0 International License (http://creativecommons.org/licenses/by/4.0/), which permits unrestricted use, distribution, and 
African countries [1, 4-6, 8-11], few data exist on infertility in Sudan [12].

Sudan is the third largest country in Africa with a population of $36,787,000$. There is a lack of proper infertility statistic in Sudan. However, infertility rate of $11.5 \%$ has been reported in 10 out of 18 Sudanese states [13]. While there is no governmental centre for assisted reproductive technology in Sudan, there are 10 private assisted reproductive technology centres in the capital Khartoum [14]. The current study was conducted to investigate the types and causes of infertility in University of Khartoum Fertility Centre, Saad Abualila Teaching Hospital in Khartoum, Sudan.

\section{Methods}

A descriptive study was conducted at University of Khartoum Fertility Centre, Saad Abualila Teaching Hospital (Khartoum, Sudan). Consecutive infertile couples referred to the centre for assisted reproduction during the period of January - December 2017 were investigated thoroughly to identify the different causes of infertility. As mentioned above the WHO definition of infertility "failure to achieve a clinical pregnancy after 12 months or more of regular unprotected sexual intercourse" was followed [2]. The medical files of infertile couples were reviewed and the data were retrieved. Information which was extracted from the records included age, type of infertility, duration, factors identified as being responsible for infertility.

At University of Khartoum Fertility Centre, Saad Abualila Teaching Hospital the couples were assessed with a comprehensive history was taken, clinical examinations, gynecologic examination, trans-vaginal ultrasonography, hematological, hormonal profile (early follicular phase follicle stimulating hormone/luteinizing hormone or antimullerian hormone in those who are not cycling, thyroid stimulating hormone, dihyroepiandosterone sulphate), hysterosalpingography (laparoscopy was performed if it was indicated). Male factor of infertility was assessed by two semen analyses three months apart. Then the factor(s) responsible for the infertility were identified and recorded. Male factors and sperm parameters were interpreted according the WHO reference values [15]. The most common parameters of male infertility were; low sperm concentration (oligospermia), poor sperm motility (asthenospermia), and abnormal sperm morphology (teratospermia) [16].

Women were diagnosed as having polycystic ovarian syndrome (PCOS) according to Rotterdam criteria [17], which was based on fulfilling two more of the following criteria: "oligomenorrhoea/anovulation, clinical or biochemical hirsutism and morphology of polycystic ovaries on ultrasonography ( $\geq 12$ follicles in each ovary measuring 2 to $9 \mathrm{~mm}$ in diameter" [17].
Women were diagnosed as having premature ovarian failure when there was no menarche (primary amenorrhea) or premature depletion of ovarian follicles/ arrested folliculogenisis (secondary amenorrhea) before the age of 40 years [18].

\section{Statistics}

Data were entered in computer using SPSS for data analyses and expressed as proportions or mean (SD). $X^{2}$ was used to compare the proportions between the two groups. $P$ value $<0.05$ at two sided was considered statistically significant.

\section{Results}

During the study period, records of 800 consecutive couples who attended the centre were reviewed. The range, mean (SD) age of the females was 16-46, 32.4 (7.4) years while that of the males was $14-60,37.5$ (7.2) years. The range, mean $(\mathrm{SD})$ of the duration of infertility was $1-21$, 4.9(3.9) years.

Five hundred and fifty one (68.9\%) couples had primary infertility, while the remainder 249(31.1\%) had secondary infertility.

Two hundred and eighty four (35.5\%) couples had male factor only, 342(42.8\%) couples had female factor only for infertility. One hundred and forty seven (18.4\%) couples had combined male and female infertility and in $27(3.4 \%)$ couples the cause of infertility was not identified, Fig. 1.

Factors identified in the female infertility (342) were; anovulation $(178,52.05 \%)$, tubal factor $(142,41.52 \%)$, uterine factor $(7,2.05 \%)$ and other/combined $(7,2.05 \%)$, Table 1. There were $164 / 800$ (20.5\%) women with PCO and 72/800 (9.0\%) women had premature ovarian failure, Fig. 1.

Azoospermia (75; 26.41\%), oligozoospermia (45, 15.85\%), asthenozoospermia $(51,17.96 \%)$, teratospermia $(15,5.28 \%)$ and mixed pathology $(101,35.56 \%)$ were the causes of the male infertility $(n=284)$, Table 2 .

Compared with primary infertility, there was significantly a higher number of female factors of infertility among couples with secondary infertility (143/551(57.4) vs. 199/249(36.1), $P<0.001$, Table 3.

\section{Discussion}

The main findings of the current study were the high rate of primary infertility $(68.9 \%)$ and high rate of female factors among infertile couples. The high rate of primary infertility in this study was similar to our previous results in Khartoum where $443(62.4 \%)$ couples had primary infertility and 267 (37.6\%) couples had secondary infertility [12]. However, this is contrary to what have been reported in Nigeria [7, 10] and in Tanzania [8] where the secondary infertility $(62.9 \%)$ predominated. In 


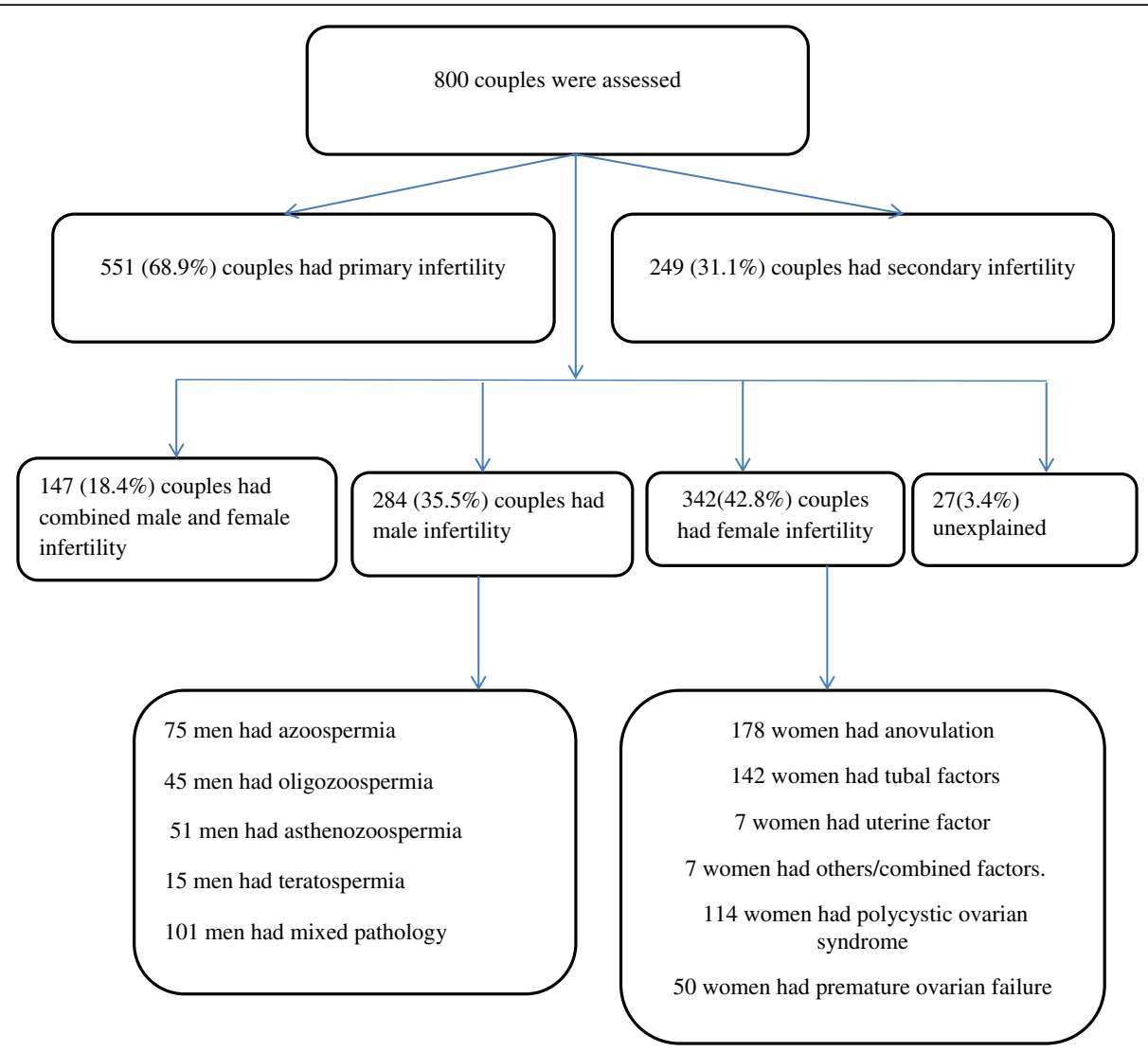

Fig. 1 the flow chart and the causes of infertility in Khartoum, Sudan

middle income countries e.g. Brazil in which over half (56.3\%) of couples referred for in-vitro fertilization centre have secondary infertility [19]. Previous studies from developed countries have shown lower rates of secondary infertility [20]. The plausible explanation for the high rate of secondary infertility is high rate $(85 \%)$ of tubal factor in Sub-Sahara Africa compared to lower rate (33\%) in infertile women worldwide [20].

In the current study $284(35.5 \%)$ couples had male infertility, 342(42.8\%) couples had female infertility, 18.4\% of the couples had combined male and female infertility and in $3.4 \%$ couples the cause of infertility was not identified. This goes with the findings of Ugwu et al., who reported that the combined male/female factors were observed in $20.4 \%$ of cases in Nigeria [7]. A previous

Table 1 causes of female infertility in Khartoum Sudan $(n=342)$

\begin{tabular}{lll}
\hline Variables & Number & proportion \\
\hline Anovulation & 178 & 52.05 \\
Tubal factor & 142 & 41.52 \\
Uterine factor & 7 & 2.05 \\
Polycystic ovarian syndrome & 114 & 33.33 \\
Premature ovarian failure & 50 & 14.62 \\
Other/combined factors & 7 & 2.05 \\
\hline
\end{tabular}

study in Benin documented that $32.2 \%$ of the couples have combined male and female factors [11]. However, other studies have reported that the causes of infertility may be associated with male factors $(40 \%)$, female factors $(40 \%)$ or the combination $(20 \%)$ of both $[4,5]$. Previous report have shown that tubal damage, male factor, anovulation and uterine factors as the main causes of infertility in Ghana [6]. Interestingly in Rwanda Dhont et al., [9] -who investigated 312 infertile women and their partners- have observed a low rate (3\%) of unexplained infertility while half $(50 \%)$ of the couples have combination of male and female causes. Likewise in Tanzania, Larsen et al., [8] have shown that female only factor was the cause of infertility in $65.9 \%$ of the couples, male only factor was identified in $6.8 \%$ of the couple and 15.2 and $12.1 \%$ of the couples had combined and unexplained

Table 2 Causes of male infertility in Khartoum Sudan $(n=284)$

\begin{tabular}{lll}
\hline Variables & Number & Proportion \\
\hline Azoospermia & 75 & 26.41 \\
Oligozoospermia & 45 & 15.85 \\
Asthenozoospermia & 51 & 17.96 \\
Teratospermia & 15 & 5.28 \\
Mixed pathology & 101 & 35.56 \\
\hline
\end{tabular}


Table 3 Comparing number (\%) of the causes of infertility between primary and secondary infertility

\begin{tabular}{llll}
\hline Factors & Primary infertility $(n=551)$ & Secondary infertility $(n=249)$ & $P$ \\
\hline Male factors & $225(40.8)$ & $59(23.7)$ & $<0.001$ \\
Female factors & $199(36.1)$ & $143(57.4)$ & $<0.001$ \\
Combined infertility & $114(20.7)$ & $33(13.3)$ & 0.011 \\
Unexplained infertility & $13(2.4)$ & $14(5.6)$ & $<0.001$ \\
\hline
\end{tabular}

infertility, respectively. A similar to low rate of unexplained infertility in our study (3.4\%), a low rate of unexplained infertility was also reported in Rwanda (3\%) [9] and in Nigeria (1.2\%) [10]. It is worth mentioning that recent evidence-based meta-analysis and systematic review results have shown a decreased sperm concentration in the African male over past 50 years [21]. Multiple factors such as infectious, environmental, genetic, and dietary factors might have a role in causation of infertility [22].

Our results have shown that mean (SD) age of the female was 32.4 (7.4) years while that of the male was 37.5 (7.2) years. This is lower than the mean age of the women [34.1(4.9) year) which was previously reported in Nigeria [7]. Moreover, previous studies from Nigeria and India have reported the average age of the females and their husbands as $36.7 / 43.7$ and $35 / 40$ years, respectively $[11,23]$. Perhaps couples have spent too much time treating infertility using conventional methods before presented to specialised centre. It is worth to be mentioned that in study in non-specialized centre in Benin Teaching Hospital, Nigeria, the mean age of women was 25 (3) years [24], however women presented at much higher (36.7 years) to IVF unit [25]. On the other hand the other reasons for presenting at advanced age include delayed marriage due to education and/or economic factors.

Our results documented the predominance of anovulation, while in most of the African countries tubal factor was the main of the cause of the female infertility [6-9]. The tubal factor could be due to infectious diseases such as Neisseria gonorrhoeae and Chlamydia trachomatis [8].

This was retrospective study and hospital-based one. Moreover, some socio-demographic variables e.g. history of smoking, alcohol intake were not available for analysis.

\section{Conclusion}

The current study showed a high rate of primary infertility and female factor predominate. Future research direction should focus on the reasons why majority of clients seek this service very late.

Abbreviations

SD: Standard deviation; WHO: World Health Organization

\section{Acknowledgments}

Not applicable.

Authors' contributions

OGE, MAA, and IA designed the study and participated in the manuscript drafting. SOS, and LIY conducted data extraction and statistical analyses. All authors read and approved the final manuscript.

Funding

There are no funding sources for this paper.

\section{Availability of data and materials}

The datasets used and/or analysed during the current study are available from the corresponding author on reasonable request.

\section{Ethics approval and consent to participate}

The study received ethical clearance from the department of Obstetrics and Gynecology, Faculty of Medicine, University of Khartoum, Sudan. The files were reviewed retrospectively and anonymously. Therefore no consent was needed.

\section{Consent for publication}

Not applicable.

\section{Competing interests}

The authors declare that they have no competing interests.

\section{Author details}

${ }^{1}$ Faculty of Medicine, University of Khartoum, PO Box 102, Khartoum, Sudan. ${ }^{2}$ Department of Obstetrics and Gynecology, Faculty of Medicine, University of Khartoum, 11111 Khartoum, Sudan. ${ }^{3}$ Saad Abu Elella Teaching Hospital, University of Khartoum Fertility Centre, Khartoum, Sudan.

Received: 9 January 2019 Accepted: 11 July 2019

Published online: 18 July 2019

\section{References}

1. Mascarenhas MN, Flaxman SR, Boerma T, Vanderpoel S, Stevens GA. National, regional, and global trends in infertility prevalence since 1990: a systematic analysis of 277 health surveys. PLoS Med. 2012;9:e1001356 Available from: https://dx.plos.org/10.1371/journal.pmed.1001356.

2. Zegers-Hochschild F, Adamson GD, de Mouzon J, Ishihara O, Mansour $\mathrm{R}$, Nygren $\mathrm{K}$, et al. International Committee for Monitoring Assisted Reproductive Technology (ICMART) and the World Health Organization (WHO) revised glossary of ART terminology, 2009. Fertil. Steril. 2009;92: 1520-4 Available from: http://linkinghub.elsevier.com/retrieve/pii/S0015 028209036887.

3. World Health Organization. Reproductive Health and Research. Reproductive health indicators : guidelines for their generation, interpretation and analysis for global monitoring. World Health Organization; 2006. at https://www. who.int/reproductivehealth/publications/monitoring/924156315x/en/ accessed4/21/2019

4. Moyo S. Indigenous knowledge systems and attitudes towards male infertility in Mhondoro-Ngezi, Zimbabwe. Cult Health Sex. 2013;15:667-79 Available from: http://www.tandfonline.com/doi/abs/10.1080/13691058.2 013.779029

5. Moyo S, Muhwati I. Socio-cultural perspectives on causes and intervention strategies of male infertility: a case study of Mhondoro-Ngezi, Zimbabwe. Afr J Reprod Health. 2013;17:89-101 Available from: http://www.ncbi.nlm. nih.gov/pubmed/24069755. 
6. Tabong PT-N, Adongo PB. Understanding the social meaning of infertility and childbearing: a qualitative study of the perception of childbearing and childlessness in northern Ghana. PLoS One. 2013;8:e54429 Available from: https://dx.plos.org/10.1371/journal.pone.0054429.

7. Ugwu EO, Onwuka Cl, Okezie OA. Pattern and outcome of infertility in Enugu: the need to improve diagnostic facilities and approaches to management. Niger J Med. 2012;21:180-4 Available from: http://www.ncbi. nlm.nih.gov/pubmed/23311187.

8. Larsen U, Masenga G, Mlay J. Infertility in a community and clinic-based sample of couples in Moshi, northern Tanzania. East Afr Med J. 2006;83:10-7 Available from: http://www.ncbi.nlm.nih.gov/pubmed/16642745.

9. Dhont N, van de Wijgert J, Vyankandondera J, Busasa R, Gasarabwe A, Temmerman M. Results of infertility investigations and follow-up among 312 infertile women and their partners in Kigali, Rwanda. Trop. Doct. 2011;41:96-101 Available from: http://journals.sagepub.com/doi/10.1258/td.2011.100410.

10. Adewunmi AA, Ottun TA, Abiara T, Chukwuma J-F, Okorie L. Sociodemographic and clinical characteristics of clients seeking assisted conception at Lagos State University teaching hospital, Ikeja, Nigeria. J Obstet Gynaecol. 2017;37:902-5 Available from: https://www.tandfonline. com/doi/full/10.1080/01443615.2017.1309365.

11. Aziken M, Orhue AA, Ezeanochie M. Socio-Demographic Characteristics Of Patients Seeking In Vitro Fertilization (IVF) at the University Of Benin Teaching Hospital, Benin City, Nigeria. Ebonyi Med J. 2010;9:2010 Available from: http://www.ajol.info/index.php/ebomed/article/view/62465.

12. Elussein EA, Magid YM, Omer MM, Adam I. Clinical patterns and major causes of infertility among Sudanese couples. Trop Dr. 2008;38(4):243-4.

13. Khalifa DS, Ahmed M. Reviewing infertility care in Sudan; socio-cultural, policy and. FW ObGyn. 2012;3:53-8,

14. Osman AA. Management of Infertility within primary health care program in Sudan. Asian J Sci Res. 2011;4:158-64 Available from: http://www.scialert. net/abstract/?doi=ajsr.2011.158.164

15. Cooper TG, Noonan E, von Eckardstein S, Auger J, Baker HWG, Behre HM, et al. World Health Organization reference values for human semen characteristics. Hum Reprod Update. 2010;16:231-45 Available from: http:// www.ncbi.nlm.nih.gov/pubmed/19934213.

16. World Health Organization. WHO Laboratory Manual for the Examination and Processing of Human Semen, 5th edn. Geneva: WHO Press; 2010. WHO Lab. Man. Exam. Process. Hum. semen, 5th ed. World Heal. Organ. 2010; WHO labora:44261

17. Rotterdam ESHRE/ASRM-Sponsored PCOS Consensus Workshop Group. Revised 2003 consensus on diagnostic criteria and long-term health risks related to polycystic ovary syndrome. Fertil. Steril. 2004;81:19-25.

18. Goswami D, Conway GS. Premature ovarian failure. Hum Reprod Update. 2005, 11:391-410 Available from: http:/www.ncbi.nlm.nih.gov/pubmed/15919682.

19. Pantoja $M$, Fernandes $A$. Indications for in vitro fertilization at a public center for reproductive health in Campinas, Brazil. Int J Gynaecol Obstet. 2015;128:14-7 Available from: http://doi.wiley.com/10.1016/j.jgo.2014.07.022.

20. Ombelet W, Cooke I, Dyer S, Serour G, Devroey P. Infertility and the provision of infertility medical services in developing countries. Hum Reprod Update. 2008;14:605-21 Available from: http://www.ncbi.nlm.nih.gov/ pubmed/18820005.

21. Sengupta P, Nwagha U, Dutta S, Krajewska-Kulak E, Izuka E. Evidence for decreasing sperm count in African population from 1965 to 2015. Afr Health Sci. 2017;17:418 Available from: http:/www.ncbi.nlm.nih.gov/pubmed/29062337.

22. Cates W, Farley T, Lancet PR-T, 1985 undefined. Worldwide patterns of infertility: is Africa different? Elsevier. [cited 2018 Nov 5]; Available from: https://www.sciencedirect.com/science/article/pii/S014067368590594X

23. Mittal S, Gurunath S, Bahadur A, Singh N, Malhotra N. Sociodemographic profile of infertile couples requesting assisted reproduction in a low -resource setting in India. Int J Gynaecol Obstet. 2010;1 10:159-60 Available from: http://www.ncbi.nlm.nih.gov/pubmed/20423737.

24. Orhue A, Aziken M. Experience with a comprehensive university hospital -based infertility program in Nigeria. Int J Gynaecol Obstet. 2008;101:11-5 Available from: http://doi.wiley.com/10.1016/j.ijgo.2007.09.034

25. Orhue AA, Aziken ME, Osemwenkha AP, Ibadin KO, Odoma G. In vitro fertilization at a public hospital in Nigeria. Int J Gynaecol Obstet. 2012;118: 56-60 Available from: http://doi.wiley.com/10.1016/j.ijgo.2012.01.022.

\section{Publisher's Note}

Springer Nature remains neutral with regard to jurisdictional claims in published maps and institutional affiliations.

\section{Ready to submit your research? Choose BMC and benefit from:}

- fast, convenient online submission

- thorough peer review by experienced researchers in your field

- rapid publication on acceptance

- support for research data, including large and complex data types

- gold Open Access which fosters wider collaboration and increased citations

- maximum visibility for your research: over $100 \mathrm{M}$ website views per year

At BMC, research is always in progress.

Learn more biomedcentral.com/submissions 